Original article

https://www.journal-imab-bg.org

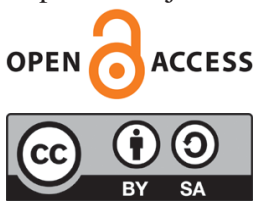

\title{
INVESTIGATION OF LIGHT INTENSITY OF LIGHT CURING UNITS AFTER DIFFERENT PERIODS OF USE
}

\author{
Georgi Georgiev ${ }^{1}$, Tsanka Dikova ${ }^{2}$, Vladimir Panov ${ }^{1}$ \\ 1) Department of Conservative Dentistry and Oral Pathology, Faculty of Den- \\ tal Medicine, Medical University of Varna, Bulgaria \\ 2) Department of Dental Materials Science and Propaedeutics of Prosthetic \\ Dental Medicine, Faculty of Dental Medicine, Medical University of Varna, \\ Bulgaria.
}

\begin{abstract}
:
Quartz-tungsten halogen light curing units (LCUs) have been the main source of light for the polymerization of resin based composites (RBCs) for several decades. Since the beginning of the 20th century, however, their use has been reduced due to the invention and improvement of LED LCUs. Various factors can cause a decrease in the light intensity of LED LCUs, one of which is diode aging. The aim of the present paper is to study the change in light intensity of LCUs after different periods of intensive use. For this purpose, the light intensity of 94 regularly used LED LCUs aged between 1 and 10 years was measured with a digital radiometer. The devices were used in conventional mode with maximum light intensity. It was found that regardless of the type and model of LCU, there is a direct relationship between the time of use and light intensity - the longer the operation period of a device is and the more used it is, the lower its intensity is. The decrease in light intensity as devices age is different for different models, as well as for different devices of the same model. In the studied LCUs with a 10 -year period of use, $77.5 \%$ have light intensity lower than the required minimum of $400 \mathrm{~mW} / \mathrm{cm}^{2}$, which makes them unusable. It can be concluded that dentists should regularly monitor and measure the light intensity of their LCUs, especially as they age, to ensure the longevity of their restorative procedures.
\end{abstract}

Keywords: light curing units, LED, light intensity, period of use

\section{INTRODUCTION:}

The initiation of the photopolymerization process represents a real revolution in dentistry. Currently, modern resin based composites (RBCs) are the first choice of restorative material for the treatment of dental caries [1-4]. This is due to a number of advantages over dental amalgam - they have very good aesthetics, do not corrode, do not stain enamel, dentin and soft tissues, do not release mercury vapour and more.

The properties of composite fillings depend on the degree of monomer-polymer conversion of the material. Ac- cording to different authors, it varies between 35 and $77 \%$ [5-7]. Incomplete polymerization leads to an increased risk of fractures, lower wear resistance, elution of unreacted monomers, lower adhesive bonding strength and faster colour change $[8,9]$. The monomer-polymer conversion depends on many factors, one of the most significant of which is the light intensity of the light curing unit (LCU).

Quartz-tungsten halogen LCUs have been the main source of light for the polymerization of RBCs for several decades. Since the beginning of the 20th century, however, their use has been reduced due to the invention and improvement of LED (light emitting diodes) LCUs. They have a number of advantages over the other types of curing devices: 1) high light intensity - from 500 to 3000 $\mathrm{mW} / \mathrm{cm}^{2}[10], 2$ ) compact wireless models with exceptional lithium-ion battery life, 3) affordable price, 4) low heat generation, 5) no need for a cooling fan [11]. Today there are hundreds of models of LED LCUs from different brands. Although they have different specifications such as shape, size, weight, price, curing modes, etc., the most important factor is the quality of the emitted light. For the adequate polymerization of a $2 \mathrm{~mm}$ composite layer in 60 seconds, it is necessary for the emitted light to have an intensity of at least $400 \mathrm{~mW} / \mathrm{cm}^{2}$, and with an intensity of less than $233 \mathrm{~mW} / \mathrm{cm}^{2}$, no effective curing can be performed, regardless of the irradiation time [12].

Various factors can cause a decrease in the light intensity of LED LCUs, such as contamination or breakage of the light guide tip, repeated sterilization [13,14], decrease in the battery charge of wireless models $[15,16]$. Diode aging can also be a reason for improper functioning. There is an inverse relationship between the clinical age of LCUs and their light intensity - the more a device is used, the more its intensity decreases [17-20], but this cannot be detected with the naked eye, as visibly bright light maybe with low intensity [21]. In addition, the insufficient light intensity can not always be compensated by prolonging the curing time [22]. Therefore, it is necessary to measure and monitor the light intensity of LCUs periodically with a radiometer to determine when the device needs to be repaired or replaced [23]. That is almost never done in dental offices, so this article is dedicated to this 
not very popular problem in dentistry.

The aim of the present paper is to study the change in light intensity of LCUs after different periods of intensive use.

\section{MATERIALS AND METHODS:}

In the present study, 94 regularly used LED LCUs aged between 1 and 10 years, of which 68 are mounted on the dental unit, and 26 are wireless and fully charged, were examined. The devices were located on the territory of the Faculty of Dental Medicine at the Medical University of Varna (Bul- garia), as well as in various dental offices in Varna.

The LCUs are divided into three groups depending on their time of use. The first group includes 23 devices from three models of different brands, measurements of which were made after 1,3 and 5 years of use. The second group is composed of 31 devices from two models of the same brand, measurements of which were made after 7 and 9 years of use. In the third group are included 40 devices from one model of the same brand, measurements of which were made after 10 years of use.

Table 1. Information about LED LCUs by the specification.

\begin{tabular}{|c|c|c|c|c|c|}
\hline \multirow{2}{*}{ Group } & $\begin{array}{c}\text { Number } \\
\text { of LCUs }\end{array}$ & Model & Brand & $\begin{array}{c}\text { Light intensity, } \\
\mathbf{m W} / \mathbf{c m}^{\mathbf{2}}\end{array}$ & $\begin{array}{c}\text { Wavelength, } \\
\mathbf{n m}\end{array}$ \\
\hline \multirow{3}{*}{1} & 19 & DB-686 DELI & $\begin{array}{c}\text { CoxoMedical } \\
\text { Instruments, China }\end{array}$ & $>1600$ & $420-480$ \\
\cline { 2 - 6 } & 3 & Smart Xpress & Bluedent, Bulgaria & 1700 & $410-490$ \\
\cline { 2 - 6 } & 1 & SK-LO29A & Spark Dental, China & 2200 & $435-480$ \\
\hline \multirow{2}{*}{2} & 21 & Masterdent & Vigodent, Bulgaria & $>700$ & $400-480$ \\
\cline { 2 - 6 } & 9 & Minident & Vigodent, Bulgaria & $>700$ & $420-480$ \\
\hline 3 & 40 & LD Max & Gnatus, Brazil & 700 & $440-480$ \\
\hline
\end{tabular}

The light intensity was measured with a digital radiometer LM-1 (Woodpecker, China), which allows measuring LCUs' output from 0 to $3500 \mathrm{~mW} / \mathrm{cm}^{2}$. Orange glasses (“blue blockers") were used to protect the operator from eye damage caused by the visible blue light. Before the start of the measurements, LCUs' tips were cleaned of contamination and stuck hard pieces of composite. LCUs were used in conventional mode with the maximum intensity of the light. The light guide tip was placed in contact with the radiometer sensor at an angle of $90^{\circ}$, three measurements were made for each device, and the mean values were recorded.

The results are analyzed statistically and presented graphically using Microsoft Excel software.

\section{RESULTS OBTAINED:}

\section{- LCUs from group 1}

The first model tested is DB-686 DELI (Coxo) (table 1). This is a LCU mounted on the dental unit, whose light intensity according to the specification is $>1600 \mathrm{~mW} /$ $\mathrm{cm}^{2}$, without specifying the exact value. Nineteen devices were tested, measurements of which were made after 1,3 and 5 years of use (fig. 1):

The graph shows the distribution of the LCUs in five subgroups depending on the measured light intensity: $<1600$ $\mathrm{mW} / \mathrm{cm}^{2}, 1600-1900 \mathrm{~mW} / \mathrm{cm}^{2}, 1900-2200 \mathrm{~mW} / \mathrm{cm}^{2}, 2200-$ $2500 \mathrm{~mW} / \mathrm{cm}^{2}$ and $>2500 \mathrm{~mW} / \mathrm{cm}^{2}$. It is noteworthy that after 1 year of operation, there are only two devices that are in the 1900-2200 $\mathrm{mW} / \mathrm{cm}^{2}$ group, and all the others have an intensity $>2200 \mathrm{~mW} / \mathrm{cm}^{2}$. None of the LCUs shows lower values than $1900 \mathrm{~mW} / \mathrm{cm}^{2}$; therefore, there are no devices in the first two subgroups with the lowest intensity.

The study of the same LCUs after 3 years of use shows a change in light intensity - it has decreased in all devices, as there are no more LCUs in the highest inten- sity group, but at the same time, there are 5 devices in the first two groups with lower intensity. Two of the LCUs have an intensity $<1600$, which is lower than the value specified by the manufacturer, and in one of the devices, the light intensity has decreased to lower than $400 \mathrm{~mW} / \mathrm{cm}^{2}$ (table 2), which is the required minimum for adequate polymerization of the RBCs.

Fig. 1. The light intensity of LCU DB-686 Deli (Coxo) after 1, 3 and 5 years of use.

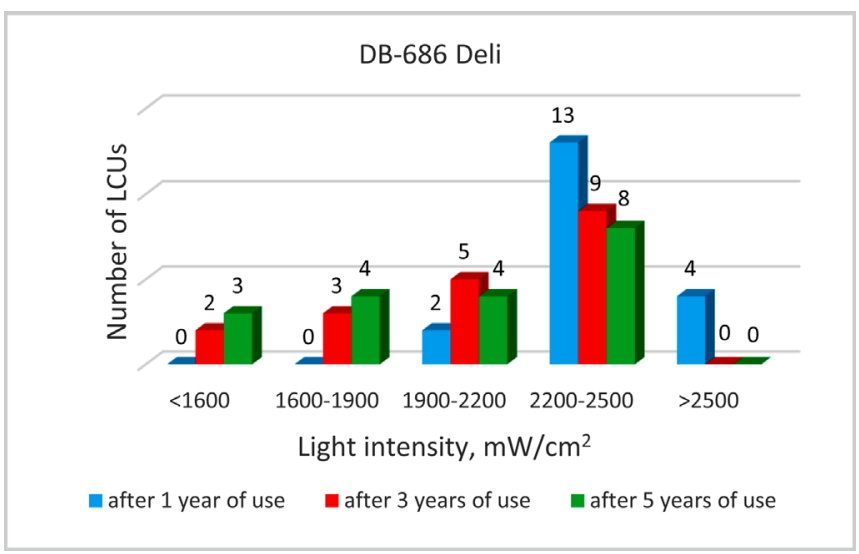

The tendency to decrease the light intensity with the aging of the devices persists in the measurement of the LCUs after 5 years of use, as they are again divided into the first four subgroups. It is noteworthy that there are already three devices with light intensity lower than specified, and in one of them, it has dropped to $325 \mathrm{~mW} / \mathrm{cm}^{2}$ (table 2), which shows that the LCU is unusable. Table 2 shows the change in light intensity of $D B-686 \mathrm{DELI}$ during the five years of use in percentage. 
Table 2. Change in light intensity of LCU DB-686 DELI (Coxo) in percentage after 3 and 5 years of use.

\begin{tabular}{|c|c|c|c|c|c|}
\hline $\begin{array}{c}\text { LCU DB-686 } \\
\text { Deli (Coxo) }\end{array}$ & $\begin{array}{c}\text { Light intensity } \\
\text { after } 1 \text { year, } \\
\mathrm{mW} / \mathrm{cm}^{2}\end{array}$ & $\begin{array}{c}\text { Light intensity } \\
\text { after 3years, } \\
\mathrm{mW} / \mathrm{cm}^{2}\end{array}$ & $\begin{array}{c}\text { Light intensity } \\
\text { after } 5 \text { years, } \\
\mathrm{mW} / \mathrm{cm}^{2}\end{array}$ & $\begin{array}{c}\text { Drop in light } \\
\text { intensity after } \\
3 \text { years, } \%\end{array}$ & $\begin{array}{c}\text { Drop in light } \\
\text { intensity after } \\
5 \text { years, \% }\end{array}$ \\
\hline 1 & 2800 & 2450 & 2300 & 13 & 18 \\
\hline 2 & 2700 & 2450 & 2300 & 9 & 18 \\
\hline 3 & 2500 & 2350 & 2300 & 6 & 8 \\
\hline 4 & 2500 & 2300 & 2300 & 8 & 8 \\
\hline 5 & 2400 & 2300 & 2250 & 4 & 6 \\
\hline 6 & 2300 & 2300 & 2250 & 0 & 2 \\
\hline 7 & 2300 & 2250 & 2200 & 2 & 4 \\
\hline 8 & 2300 & 2250 & 2200 & 2 & 4 \\
\hline 9 & 2300 & 2200 & 2100 & 4 & 9 \\
\hline 10 & 2200 & 2100 & 1950 & 5 & 11 \\
\hline 11 & 2200 & 2050 & 1900 & 7 & 14 \\
\hline 12 & 2200 & 1950 & 1850 & 11 & 16 \\
\hline 13 & 2200 & 1900 & 1700 & 14 & 23 \\
\hline 14 & 2200 & 1900 & 1700 & 14 & 23 \\
\hline 15 & 2200 & 1850 & 1600 & 16 & 27 \\
\hline 16 & 2200 & 1850 & 1550 & 16 & 30 \\
\hline 17 & 2200 & 1725 & 1450 & 16 & 34 \\
\hline 18 & 2000 & 1500 & 1100 & 25 & 45 \\
\hline 19 & 1900 & 400 & 325 & 79 & 83 \\
\hline
\end{tabular}

The table shows that the aging of the LCUs affects their light intensity differently. The change in some devices is barely noticeable within $5-10 \%$, while in others, it is drastic and reaches $83 \%$. On average, for all 19 LCUs, the decrease in light intensity in the third year compared to the first is $13.2 \%$, and in the fifth year compared to the first is $20.1 \%$.

The second tested model is $S K-L 029 A$ (Spark Dental) (table 1). This is a wireless LCU with a light intensity of $2200 \mathrm{~mW} / \mathrm{cm}^{2}$, according to the specification. One device was studied, measurements of which were made after 1, 3 and 5 years of its use (fig. 2):

The graph shows that even after 1 year of use, the light intensity of the LCU has decreased by $9.1 \%$, after 3 years - by $37.5 \%$, and after 5 years - by more than $50 \%$.

The third tested model from group 1 is Smart Xpress (Bluedent) (table 1). This is a wireless LCU with a light intensity of $1700 \mathrm{~mW} / \mathrm{cm}^{2}$ by the specification. Three devices were studied, measurements of which were made after 1, 3 and 5 years of use (fig. 3). The graph shows that the light intensity specified by the manufacturer has maintained the same values after 1 and 3 years of use in
Fig. 2. Change in light intensity of LCU SK-L029A (Spark Dental) in 5 years interval

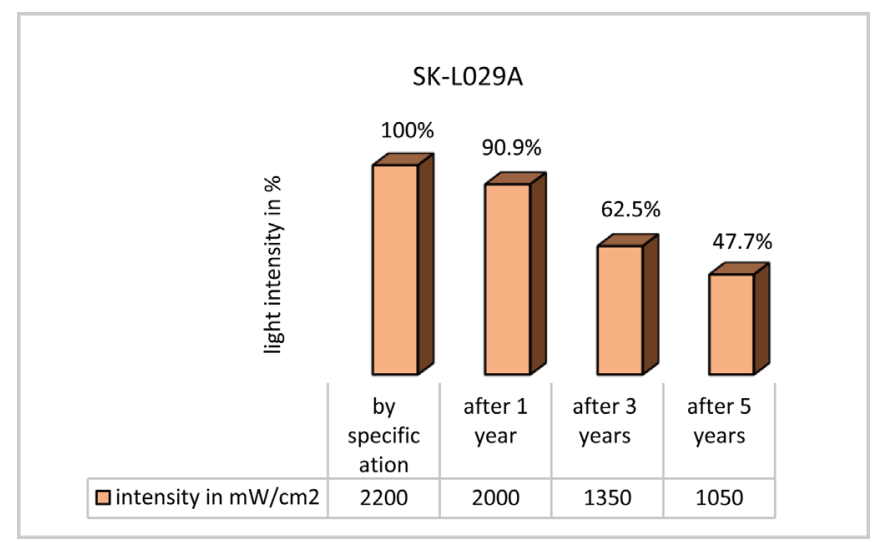

all three devices. A decrease in the intensity is observed in the measurement after 5 years in all three LCUs, as the reduction in percentage is $10.3 \%, 14.7 \%$ and $23.5 \%$, respectively, which makes an average reduction of $16.2 \%$ for the three devices. 
Fig. 3. Change in light intensity of LCU Smart Xpress (Bluedent) in 5 years interval.

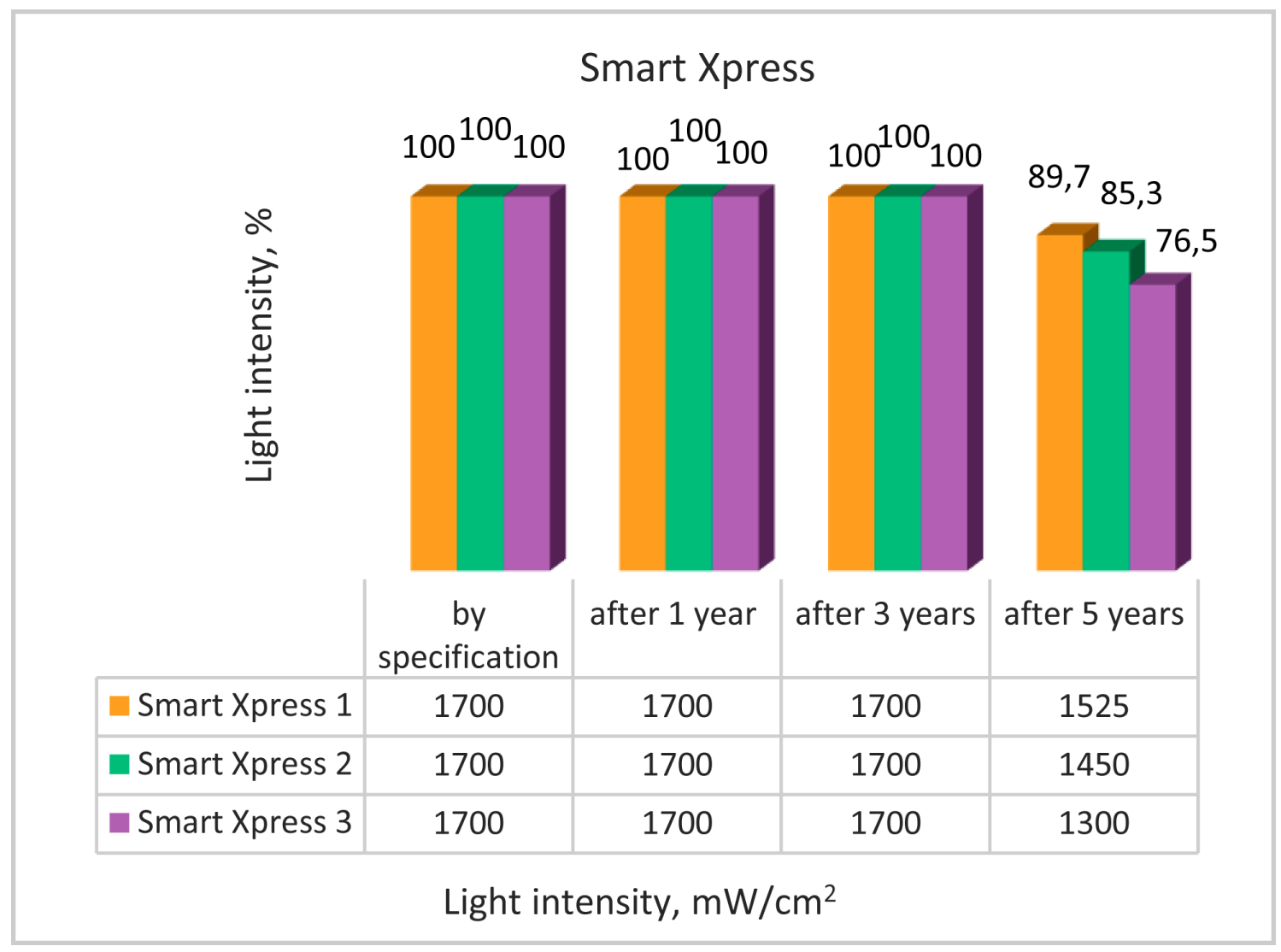

\section{- LCUs from group 2}

Two models from the same brand are included in group 2 - Minident (Vigodent) è Masterdent (Vigodent) (table 1). Minident is a LCU mounted on the dental unit, whose light intensity by specification is $>700 \mathrm{~mW} / \mathrm{cm}^{2}$. Nine devices were tested after 7 years of use. The measured light intensity of all devices is in the range of 800$950 \mathrm{~mW} / \mathrm{cm}^{2}$, which shows that in none of the LCUs, the light intensity has not dropped below the values set by the manufacturer.

Masterdent is a wireless LCU whose light intensity by specification is $>700 \mathrm{~mW} / \mathrm{cm}^{2}$. Twenty-one devices were tested after 9 years of use (fig. 4 ).

Fig. 4. The light intensity of LCU Masterdent (Vigodent) after 9 years of use.

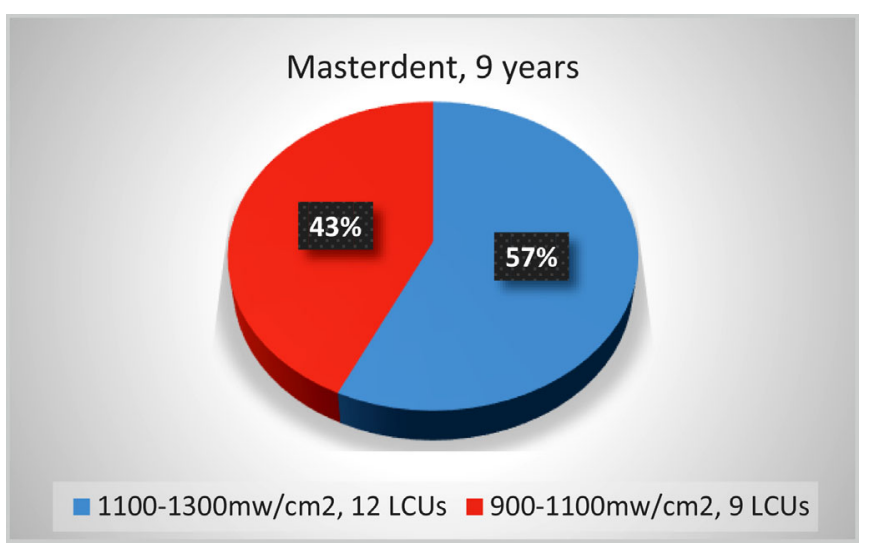

The graph shows that 12 of the LCUs have light intensity between 1100 and $1300 \mathrm{~mW} / \mathrm{cm}^{2}(57 \%)$, and 9 LCUs have intensity between 900 and $1100 \mathrm{~mW} / \mathrm{cm}^{2}$. None of the LCUs shows a drop below the values $\uparrow$ set by the manufacturer.

\section{- LCUs from group 3}

LCUs from group 3 are LD Max (Gnatus) (table 1). They are mounted on the dental unit with a light intensity of $700 \mathrm{~mW} / \mathrm{cm}^{2}$ by the specification. Measurements were made on 40 devices after 10 years of use (fig. 5).

Fig. 5. The light intensity of LCU LD Max (Gnatus) after 10 years of use.

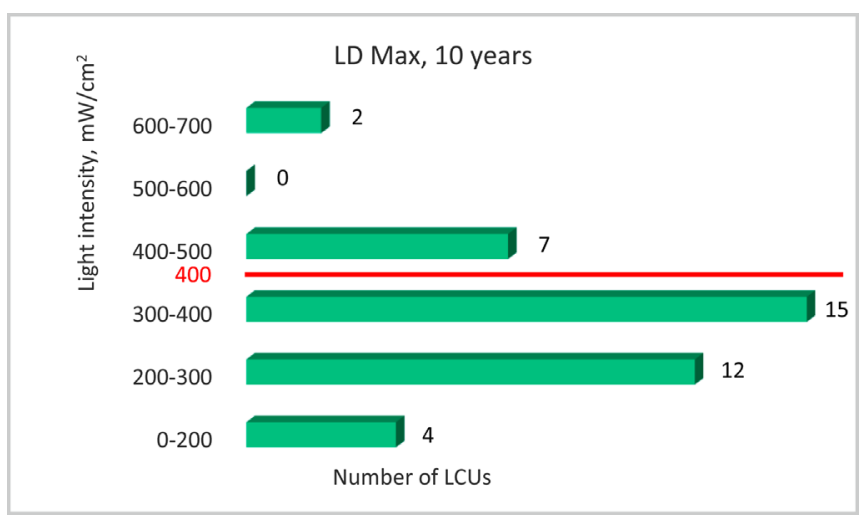


The graph shows that 2 LCUs have intensity between 600 and $700 \mathrm{~mW} / \mathrm{cm}^{2}, 7$ LCUs have intensity between 400 and $500 \mathrm{~mW} / \mathrm{cm}^{2}$, and all the other 31 devices have intensity $<400 \mathrm{~mW} / \mathrm{cm}^{2}$, even as in 4 of them, the measurement shows $0 \mathrm{~mW} / \mathrm{cm}^{2}$. The change in the light intensity in percentages compared to the one specified by the manufacturer is presented in fig. 6 .

Fig. 6. The light intensity of LCU LD Max (Gnatus) after 10 years of use represented as a percentage of the light intensity specified by the manufacturer.

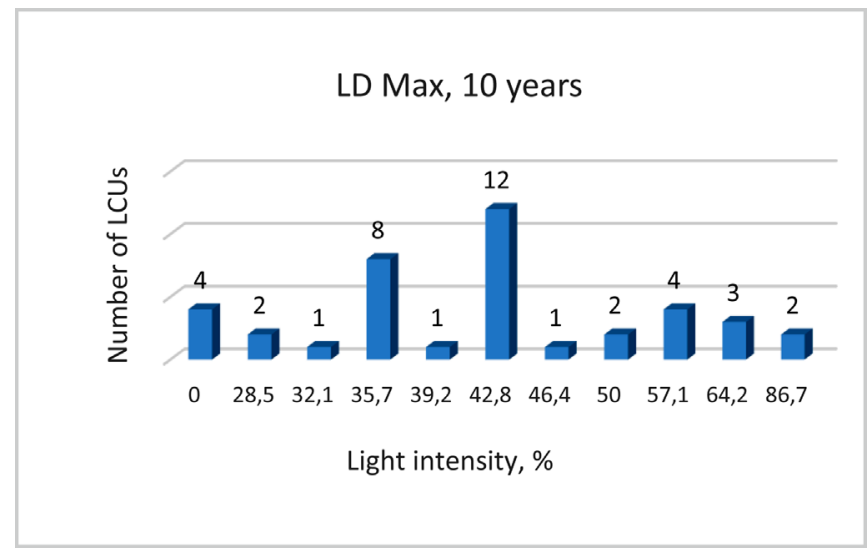

The graph shows that in 26 out of 40 devices, the decrease in light intensity is more than $50 \%$, and in 4 devices, there is a $100 \%$ drop.

\section{DISCUSSION:}

In the present study, the light intensity of 94 LED LCUs was measured during different periods of their use - from 1 year up to 10 years. A direct relationship was established between the clinical age of the devices and their light intensity - the older the LCU is and the more used it is, the lower its intensity is. Several other authors have obtained similar results in their researches [17-21].

The minimum light intensity of the LCU shall be at least $400 \mathrm{~mW} / \mathrm{cm}^{2}$ with 60 seconds of irradiation time [12]. However, according to our study, $63 \%$ of the dentists light cure each composite layer for 20 seconds [24], which requires a higher intensity to achieve adequate polymerization of the material. The decrease in light intensity of LCUs with advancing clinical age is unfavorable for two reasons. The first is that the light intensity may fall below the required minimum of 400 $\mathrm{mW} / \mathrm{cm}^{2}$, which will lead to the impossibility of achieving an optimal degree of monomer-polymer conversion. The second reason is that even if the intensity is greater than $400 \mathrm{~mW} / \mathrm{cm}^{2}$, it can be significantly lower than the one specified by the manufacturer. Very often, convinced by the characteristics of their LCUs, dentists reduce the irradiation time, and this, in turn, can lead to improper polymerization of the material due to incorrect light curing regime (the combination of light intensity and curing time).

In the first group of LCUs (24 devices from three different brands), the measurements were made after 1, 3 and 5 years of use. It is noteworthy that in only one device, the light intensity measured was $<400 \mathrm{~mW} / \mathrm{cm}^{2}$, which makes it unusable. At the same time, however, all devices showed a decrease in intensity varying from $2 \%$ to $83 \%$. This difference is due, on the one hand, to the difference in the models and brands, and on the other hand - to the different intensity of use (the more curing cycles one LCU performs - the more its light intensity decreases) [12]. The comparative analysis of the average decrease in percentages after 3 years of use shows that it is the smallest in Smart Xpress (Bluedent) - 0\%, followed by DB-686 DELI (Coxo) - 13.2\%, and the largest in $S K-L 029 A$ (Spark Dental) - 37.5. This sequence is also preserved after 5 years of operation, respectively Smart Xpress - 16.2\%, DB-686 DELI - 20.1\%, and SK-LO29A $52.3 \%$.

The second group of LCUs includes 30 devices from 2 different models of the same brand - Minident (Vigodent) and Masterdent (Vigodent), tested respectively after 7 years and 9 years of use. It should be noted that the light intensity of all tested LCUs is between 800 $\mathrm{mW} / \mathrm{cm}^{2}$ and $1300 \mathrm{~mW} / \mathrm{cm}^{2}$. None of the devices has an intensity below the required minimum of $400 \mathrm{~mW} / \mathrm{cm}^{2}$, and none of them has intensity less than $700 \mathrm{~mW} / \mathrm{cm}^{2}$, as specified by the manufacturer. These results confirm once again the thesis that the model and frequency of use are of great importance for the reduction of light intensity with the progression of the clinical age of the devices.

The most drastic change in light intensity was found in LCUs of the third group - LD Max (Gnatus) 31 out of 40 devices or $77.5 \%$ are unusable because the light intensity is below the minimum required $400 \mathrm{~mW} /$ $\mathrm{cm}^{2}$. At the time of the study, these LCUs have been subject to daily use without dentists being informed of the need to repair or replace the devices. The malfunction of the LCUs, in turn, leads to inadequate polymerization of RBCs and long-term failure of restorative procedures.

The present study shows that dentists should be well acquainted with the characteristics of their LCUs and periodically check them with a radiometer because as devices age, their light intensity decreases. The measurement is necessary for two reasons: first, because the bright blue light from the LCU can have a very low intensity and second, because the top surface of the composite filling may be hard, but at the bottom of the restoration, the degree of monomer-polymer conversion may be low. In some cases, the drop in light intensity is insignificant, but in others, it is drastic and requires the devices to be repaired or replaced.

The necessity for regular measurement of LCUs with a radiometer is also confirmed by another of our studies [16], which shows that in some wireless models, light intensity decreases with the discharge of the battery. This, in combination with the aging of the devices, can cause inefficient polymerization of the composite restoration, which will be the reason for its low quality and short life. 


\section{CONCLUSIONS:}

In the present paper, the change of light intensity of LCUs after different periods of use was studied. It was found that:

- Regardless of the type and model of LCUs, there is a direct relationship between the time of use and light intensity - the longer the period of operation of a device is and the more used it is, the lower its intensity is.
- The decrease in light intensity as devices age is different for different models, as well as for different devices of the same model.

- In the studied LCUs with a 10-year period of use, $77.5 \%$ have light intensity lower than the required minimum of $400 \mathrm{~mW} / \mathrm{cm}^{2}$, which makes them unusable.

- Dentists should regularly monitor and measure the light intensity of their LCUs, especially as they age, to ensure the longevity of their restorative procedures.

\section{REFERENCES:}

1. Domejean S, Leger S, Maltrait M, Espelid I, Tveit AB, Tubert-Jeannin S. Changes in occlusal caries lesion management in France from 2002 to 2012: a persistent gap between evidence and clinical practice. Caries Res. 2015 Jun;49(4):40816. [PubMed]

2. Eklund SA. Trends in dental treatment, 1992 to 2007. J Am Dent Assoc. 2010 Apr;141(4):391-9. [PubMed]

3. Lynch CD, McConnell RJ, Wilson $\mathrm{NH}$. Trends in the placement of posterior composites in dental schools. J Dent Educ. 2007 Mar;71(3):430-434. [PubMed]

4. Opdam NJ, Bronkhorst E, Roeters J, Loomans BA. Longevity and reasons for failure of sandwich and total-etch posterior composite resin restorations. J Adhes Dent. 2007 Oct;9(5):469-75. [PubMed]

5. Imazato S, McCabe JF, Tarumi H, Ehara A, Ebisu S. Degree of conversion of composites measured by DTA and FTIR. Dent Mater. 2001 Mar;17(2):178-83. [PubMed]

6. Peutzfeldt A, Sahafi A, Asmussen E. Characterization of resin composites polymerized with plasma arc curing units. Dent Mater. 2000 Sep;16(5):330-6. [PubMed]

7. Ruyter I, Svendsen SA. Remaining methacrylate groups in composite restorative materials. Acta Odontol Scand. 1978;36(2):75-82. [PubMed]

8. Indzhov B. [Obturatio cavi dentis.] [in Bulgarian] 7print, Sofia. 2009. Chapter 2, p.19-34.

9. Krifka S, Seidenader C, Hiller KA,
Schmalz G, Schweikl H. Oxidative stress and cytotoxicity generated by dental composites in human pulp cells. Clin Oral Invest. $2012 \mathrm{Feb} ; 16(1): 215-24$. [PubMed]

10. Chen YC, Ferracane JL, Prahl SA. Quantum yield of conversion of the photoinitiator camphorquinone. Dent Mater. 2007 Jun;23(6):655-64. [PubMed]

11. Al-Ahdal K, Ilie N, Silikas N, Watts D.C. Polymerization kinetics and impact of post polymerization on the degree of conversion of bulk-fill resin-composite at clinically relevant depth. Dent Mater. 2015 Oct;31(10):1207-13. [PubMed]

12. Rueggeberg FA, Caughman WF, Curtis JW, Jr. Effect of light intensity and exposure duration on cure of resin composite. Oper Dent. 1994 Jan-Feb;19(1):26-32. [PubMed]

13. Kofford KR, Wakefield CW, Nunn ME. The effect of autoclaving and polishing techniques on energy transmission of light-curing tips. Quintessence Int. 1998 Aug;29(8):491-6. [PubMed]

14. Dugan WT, Hartleb JH. Influence of a glutaraldehyde disinfecting solution on curing light effectiveness. Gen Dent. 1989 Jan-Feb;37(1):40-3. [PubMed]

15. Tongtaksin A, Leevailoj C. Battery charge affects the stability of light intensity from lightemitting diode light-curing units. Oper Dent. 2017 Sep-Oct;42(5), 497-504. [PubMed]

16. Georgiev G, Panov V, Dikova T. Investigation of light intensity of wireless LED light curing units. J Techn Univ
Gabrovo. 2020; 60:40-45.

17. Barghi N, Berry T, Hatton C. Evaluating intensity output of curing lights in private dental offices. J Am Dent Assoc. 1994 Jul;125(7):992-6. [PubMed]

18. Martin FE. A survey of the efficiency of visible light curing units. $J$ Dent. 1998 Mar;26(3):239-43. [PubMed]

19. Poulos JG, Styner DL. Curing lights: changes in intensity output with use over time. Gen Dent. 1997 Jan-Feb;45(1): 70-3. [PubMed]

20. Friedman J, Hassan R. Comparison study of visible curing lights and hardness of light-cured restorative materials. $J$ Prosthet Dent. 1984 Oct;52(4):504-6. [PubMed]

21. Omidi B, Gosili A, Jaber-Ansari M, Mahdkhah A. Intensity output and effectiveness of light curing units in dental offices J Clin Exp Dent. 2018 Jun;10(6): e555-e560. [PubMed]

22. Miyazaki M, Hattori T, Ichiishi Y, Kondo M, Onose H, Moore BK. Evaluation of curing units used in private dental offices. Oper Dent. 1998 Mar-Apr;23(2): 50-4. [PubMed]

23. Barghi N, Fischer DE, Pham T. Revisiting the intensity output of curing lights in private dental offices. Compend Contin Educ Dent. 2007 Jul;28(7):380-4, quiz 3856. [PubMed]

24. Georgiev G. Factors associated with light curing units: a questionnaire survey. Scr Sci Med Dent. 2019;5(2):37-43. [Crossref]

Please cite this article as: Georgiev G, Dikova T, Panov V. Investigation of light intensity of light curing units after different periods of use. $J$ of IMAB. 2021 Oct-Dec;27(4):4164-4169. DOI: https://doi.org/10.5272/jimab.2021274.4164

Address for correspondence:

Georgi Georgiev

Department of Conservative Dentistry and Oral Pathology, Faculty of Dental Medicine, Medical University of Varna

84, Tsar Osvoboditel Blvd, 9000 Varna, Bulgaria

E-mail: dr_g_georgiev88@abv.bg, 